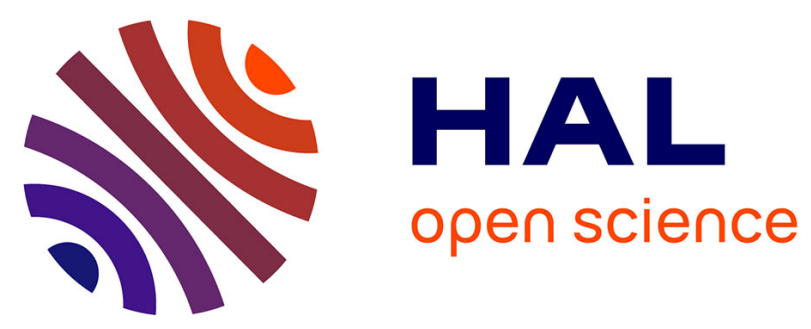

\title{
The mannose 6-phosphate receptor targeted with porphyrin-based periodic mesoporous organosilica nanoparticles for rhabdomyosarcoma theranostics
}

Morgane Daurat, Christophe Nguyen, Sofia Dominguez Gil, Vincent Sol, Vincent Chaleix, Clarence Charnay, Laurence Raehm, Khaled El Cheikh, Alain Morère, Michele Bernasconi, et al.

\section{To cite this version:}

Morgane Daurat, Christophe Nguyen, Sofia Dominguez Gil, Vincent Sol, Vincent Chaleix, et al.. The mannose 6-phosphate receptor targeted with porphyrin-based periodic mesoporous organosilica nanoparticles for rhabdomyosarcoma theranostics. Biomaterials Science, 2020, 8 (13), pp.3678-3684. 10.1039/d0bm00586j . hal-02912281

\section{HAL Id: hal-02912281 \\ https://hal.umontpellier.fr/hal-02912281}

Submitted on 26 Nov 2020

HAL is a multi-disciplinary open access archive for the deposit and dissemination of scientific research documents, whether they are published or not. The documents may come from teaching and research institutions in France or abroad, or from public or private research centers.
L'archive ouverte pluridisciplinaire HAL, est destinée au dépôt et à la diffusion de documents scientifiques de niveau recherche, publiés ou non, émanant des établissements d'enseignement et de recherche français ou étrangers, des laboratoires publics ou privés. 


\section{Mannose 6-phosphate receptor targeted with porphyrin-based periodic mesoporous organosilica nanoparticles for Rhabdomyosarcoma theranostic}

Morgane Daurat, $\dagger^{\mathrm{a}}$ Christophe Nguyen, $\boldsymbol{\dagger}^{\mathrm{b}}$ Sofia Dominguez Gil, $\dagger^{\mathrm{c}}$ Vincent Sol, ${ }^{\mathrm{d}}$ Vincent Chaleix, ${ }^{\mathrm{d}}$ Clarence Charnay, ${ }^{\mathrm{c}}$ Laurence Raehm, ${ }^{\mathrm{c}}$ Khaled El Cheikh, ${ }^{\mathrm{a}}$ Alain Morère, ${ }^{\mathrm{b}}$ Michele Bernasconi, ${ }^{\mathrm{e}}$ Andrea Timpanaro, ${ }^{\mathrm{e}}$ Marcel Garcia, ${ }^{\mathrm{a}}$ Frédérique Cunin, ${ }^{\mathrm{c}}$ Jochen Roessler, ${ }^{\mathrm{e}}$ Jean-Olivier Durand ${ }^{* \mathrm{c}}$ and Magali Gary-Bobo* ${ }^{\mathrm{b}}$

Recently, we described porphyrin-based periodic mesoporous organosilica (PMO) nanoparticles synthesized from a large functional octatriethoxysilylated porphyrin precursor. The framework of the nanoparticles was formed by J-aggregates of porphyrins allowing two-photon excitation photodynamic therapy (TPE-PDT) and NIR imaging. In the present work, these PMO were grafted with polyethylene glycol (PEG) moieties and an analogue of mannose 6-phosphate functionalized on anomeric position (AMFA). AMFA are known to efficiently target mannose 6-phosphate receptors (M6PR) which are over-expressed in various cancer cell lines (breast, prostate). Here, we demonstrated that M6PR was also over-expressed in rhabdomyosarcoma cells (RMS) and could be efficiently targeted with PMO-AMFA allowing TPE imaging and TPE-PDT of RMS cells. Furthermore the same treatment did not affect healthy myoblasts which do not over-express M6PR suggesting a specificity in its biomedical action. 


\section{Introduction}

Rhabdomyosarcomas (RMS) are the most common soft tissue sarcomas of childhood. There are two major subtypes, the embryonal and the alveolar (most aggressive) RMS. Despite intensified, multimodality treatments, the overall survival of high-risk population has remained at $5 \%$ to $20 \%$ over the last decades. This rate is insufficient, therefore new innovative selective treatments based on nanomedicine are urgently needed. Very few examples of nanoparticles for treatment of RMS have been described in the literature. Abraxane and liposomal vincristine have been investigated in RMSxenografted mice, ${ }^{1,2}$ magnetic drug targeting was reported in rat models of $\mathrm{RMS}^{3}{ }^{3}$ chitosan nanoparticles have been used to silence TGF $\beta 1$ (transforming growth factor) in cells with small hairpin RNA ${ }^{4}$ or mesoporous silica nanoparticles functionalized with polyethyleneimine have been used in cells to silence ELMO1, a protein involved in cell migration. ${ }^{5}$ None of these nanoparticles were functionalized with a biomolecule to target RMS. Targeting an overexpressed receptor in cancer research is very important to differentiate between malignant and normal tissues. Gold nanoparticles have been functionalized with TAT peptide to target RMS cells, and induced cell death ${ }^{6}$ but TAT peptide is not specific for RMS. Liposomes loaded with tubulin binding epothilone B agent were developed in order to target RMS. These liposomes have been shown to inhibit endothelial and tumor cell viability to the same extends as the free drug. Furthermore, potent antitumor growth activity could be demonstrated in vivo by using vascular endothelial cell targeting. Indeed the RGD peptide was attached on the surface of the liposomes. These liposomes interact with the integrin receptor and show a beneficial effect in comparison to the untargeted formulation, by increasing cumulative survival of mice bearing RMS. ${ }^{7}$

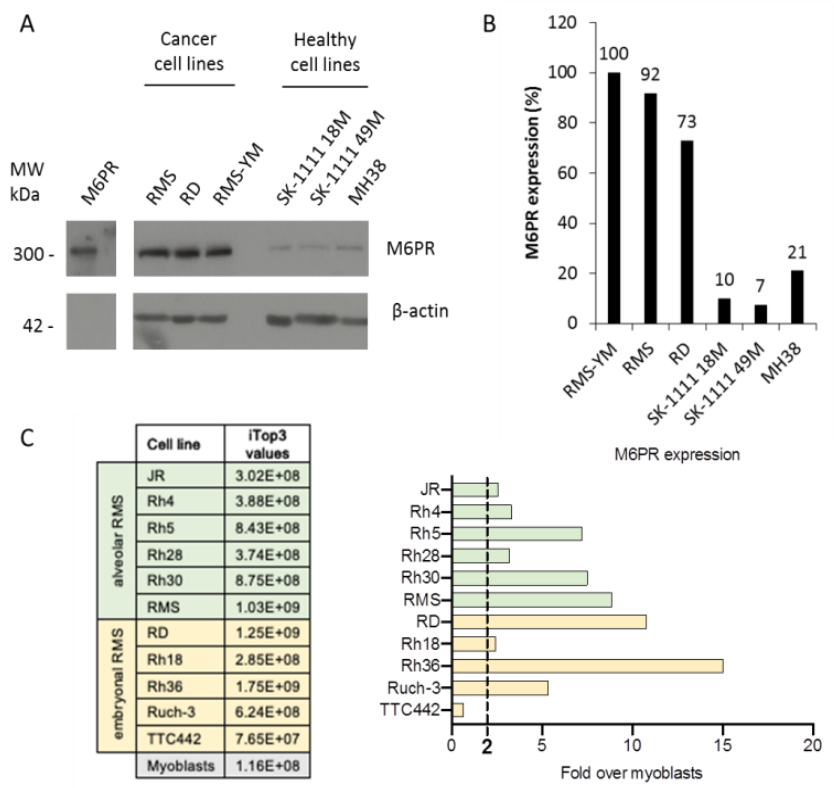

However, the RGD peptide is not sufficiently specific for RMS as integrins are also over-expressed in all the vascular endothelial cells of children.

Identification of cation-independent mannose 6-phosphate receptor (M6PR) overexpression on prostate cancer cells ${ }^{8}$ led us to study the expression level of M6PR on other types of cancer such as RMS. In the present paper, overexpression of M6PR on RMS cells compared to healthy myoblasts was studied and confirmed. We therefore decided to target RMS cells using M6PR pathway and more particularly using analogues of mannose 6-phosphate functionalized on anomeric moiety (AMFA) grafted on nanoparticles.

We recently synthesized very efficient porphyrin-based periodic mesoporous organosilica nanoparticles (PMOsPOR NPs, $250 \mathrm{~nm}$ diameter) showing interconnected cavities (from 10 to $80 \mathrm{~nm}$ ) for breast cancer treatment using two-photon excited photodynamic therapy (TPE-PDT). ${ }^{9}$ For this, a large functional octatriethoxysilylated porphyrin precursor was condensed without any silica source. The framework of the nanoparticles was formed with J-aggregates of porphyrins inside the pore of the walls allowing two-photon excitation (TPE). ${ }^{10}$ TPE is of particular interest for biological applications because it allows a deep penetration of the near-infrared beam down to $2 \mathrm{~cm}$ in soft tissues and a high spatiotemporal resolution for imaging and cancer detection. Importantly, TPE-PDT has demonstrated a high potential for cancer therapy, in particular, the treatment of small-sized tumor. ${ }^{11}$

Therefore, we presented here the combination of PMO with AMFA to target M6PR overexpressed in RMS cells of both phenotypes, embryonal and alveolar subtypes for TPE-PDT of RMS. The strong therapeutic potential and selectivity of PMO grafted with PEG and AMFA were demonstrated.

\section{Results and discussion}




\section{Overexpression of M6PR on RMS cells}

The first step of this work was the study of M6PR expression on RMS cells with embryonal and alveolar subtype and healthy myoblasts. For this, the protein expression level of M6PR in 3 different RMS cells lines and in healthy myoblasts was analysed by Western blot (Figure 1).

As showed in Figure 1A, the protein expression level of M6PR is clearly higher in RMS cell lines than in healthy myoblasts. The quantification of M6PR level by Image $J$ software corrected by the expression level of an invariant ( $\beta$-actin) indicated that in mean, there was a 7 fold-higher M6PR expression in RMS cells than in healthy cells. To confirm and to expand these data, we performed proteomic analysis of the membrane fraction of several RMS cell lines. Healthy myoblasts were used as control (Figure 1C). These results confirmed a higher expression of M6PR in RMS cell lines of both alveolar and embryonal subtype. This suggested that the increase in M6PR expression could be considered as a biomarker of RMS development.

Figure 1. M6PR expression in different cell lines. (A) The cell extracts ( $25 \mu \mathrm{g})$ were analyzed by Western blots using human M6PR or $\beta$-actin antibodies. $\beta$-actin is a control for total protein loading. (B) Quantification with Image J software of $300 \mathrm{kDa}$ M6PR protein corrected by $\beta$-actin expression. RMS-YM cells are considered as $100 \%$. (C) Proteomics analysis of M6PR expression in a panel of RMS cell lines. Membrane proteins were enriched with two-step centrifugation protocol and analysed by HPLC-MS. iTop3 values were calculated from the sum of the intensity of the 3 most intense peptides of each Leading Razor Protein.

\section{Synthesis of PMO grafted with PEG and AMFA}

Porphyrin-based PMO nanoparticles were first synthesized following our recently described procedure (Figure $2 \mathrm{~A}) .^{9}$ We then investigated the functionalization of PMO with AMFA (Figure 2B). For this, aminoundecyltriethoxysilane and PEG triethoxysilane were first grafted on the surface of PMO following a method we published on mesoporous silica nanoparticles (MSN) of $20 \mathrm{~nm}$ diameter. ${ }^{19}$ Then AMFA was grafted on the surface of functionalized PMO. Here, the AMFA used was the M6C-PhSq (Figure 2B), and the reaction of its squarate moiety with the amino groups led to a covalent attachment of AMFA on the surface of PMO. The different steps of the functionalization were monitored by DLS and zeta potential. PMO nanoparticles showed a negative zeta potential (-38.3 mV, after extraction of the surfactant) in agreement $\mathrm{Si}-\mathrm{O}^{-}$groups on the surface. The DLS showed $245 \mathrm{~nm}$ hydrodynamic diameter. After functionalization with $\mathrm{NH}_{2}$ groups and PEG, the hydrodynamic diameter increased to $310 \mathrm{~nm}$ and zeta potential was $+18.3 \mathrm{mV}$ (after extraction of the

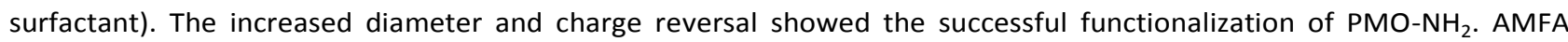
grafting level was quantified by HPLC demonstrating that $66 \mu \mathrm{g}$ of AMFA were grafted per mg of PMO. This reaction led to a $399 \mathrm{~nm}$ hydrodynamic diameter (Figure 2C) and a negative zeta potential of $-22.9 \mathrm{mV}$ in agreement with the anchoring of the carbohydrate moiety on the surface of the nanoparticles. TEM imaging showed homogenous dispersion and a large

A

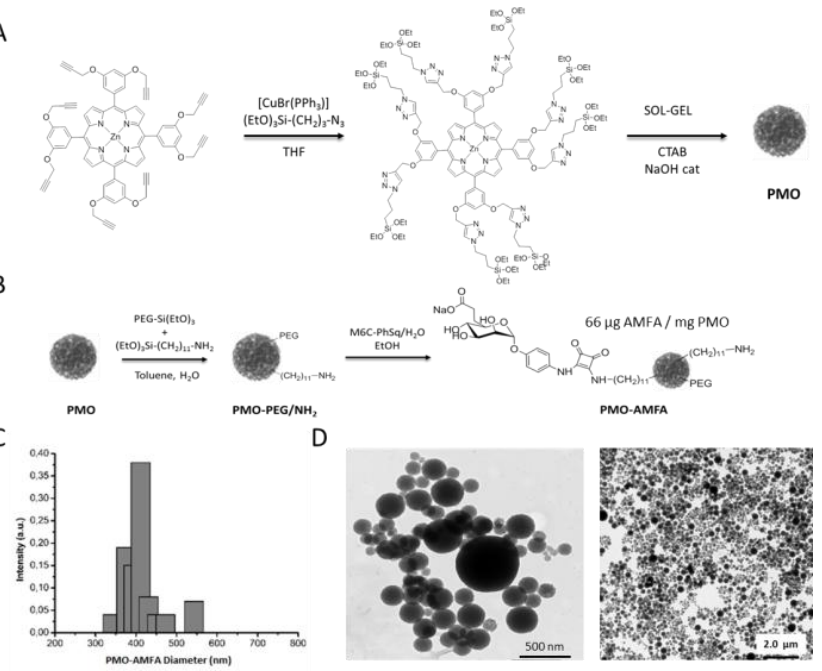

amount of small-sized nanoparticles (Figure 2D).

Figure 2. Synthesis and characterization of PMO-AMFA. (A) Synthesis of PMO. (B) Schematic representation of coupling of the mannose 6-carboxylate with a phenyl squarate arm (M6C-PhSq) also called AMFA in order to obtained PMO-AMFA. (C) DLS in intensity of PMO-AMFA. (D) Microscopy images of PMO-AMFA by TEM at different magnifications. 


\section{Biocompatibility of PMO on different cell lines}

A cytotoxic study was carried out with increasing concentrations of PMO grafted with PEG and AMFA, for a 3 days incubation time. This study was performed on one RMS and one healthy cell line: RMS-YM and SK-1111, respectively. These data demonstrated that for both cell lines, the batch of PMO, which were grafted with PEG and AMFA (PMOAMFA), did not show any cytotoxicity (Figure 3 ). In contrast, pristine $\mathrm{PMO}$ (here called $\mathrm{PMO}$ ) and $\mathrm{PMO}-\mathrm{PEG}_{\mathrm{N}} \mathrm{NH}_{2}$ generated slight cell death. In fact, in RMS-YM cells, the incubation with $\mathrm{PMO}$ at $100 \mu \mathrm{g} \cdot \mathrm{mL}^{-1}$ induced $30 \%$ cell death (Figure 3A). In SK-1111, PMO and PMO-PEG/ $\mathrm{NH}_{2}$ at $100 \mu \mathrm{g} \cdot \mathrm{mL}^{-1}$ induced approximately the same percentage of cell death (Figure $3 \mathrm{~B}$ ). However, up to $40 \mu \mathrm{g} \cdot \mathrm{mL}^{-1}$ no significant cell death was observed in any cell lines. So this concentration was chosen for further biological experiments.

Figure 3. Cytotoxicity of PMO on RMS and healthy cells. (A) RMS-YM cells and (B) SK-1111 healthy cells were treated with increasing concentrations of nanoparticles. After three days of incubation, a MTT assay was performed. Data are presented as (mean \pm SEM), $n=2$.

\section{Study of TPE-PDT and fluorescence imaging potential}

The biological activity and more particularly the ability of PMO-AMFA to target and treat RMS cells under near infrared two-photon excitation was studied (Figure 4). For this RMS-YM cancer cells and SK-1111 healthy cells were incubated with $40 \mu \mathrm{g} \cdot \mathrm{mL}^{-1}$ of PMO, PMO-PEG/NH $\mathrm{NH}_{2}$ or PMO-AMFA for $16 \mathrm{~h}$. Then, the cells were irradiated or not at $800 \mathrm{~nm}$ for a short time $\left(3 \times 1.57 \mathrm{~s}\right.$ ) at maximal laser power (Figure 4A-B). PMO and PMO-PEG/NH $\mathrm{NH}_{2}$ induced $62 \%$ and $57 \%$ RMS-YM cell death, respectively, and $50 \%$ and $51 \%$ on SK-1111 healthy cells. Interestingly, PMO-AMFA was highly efficient on cancer cells by inducing $94 \%$ RMS-YM cell death after TPE. In contrast, PMO-AMFA did not induce any significant phototoxicity on healthy cells. This result demonstrated the importance of the targeting and the specificity of PMO-AMFA for RMS.

The M6PR involvement in the active endocytosis of PMO-AMFA was demonstrated by the addition in culture medium of M6P, which is M6PR natural ligand. This experiment is based on a competitive inhibition of PMO-AMFA endocytosis by M6P. RMS-YM cells were incubated for $4 \mathrm{~h}$ with PMO-AMFA in the presence or absence of M6P excess (10 mM). Under
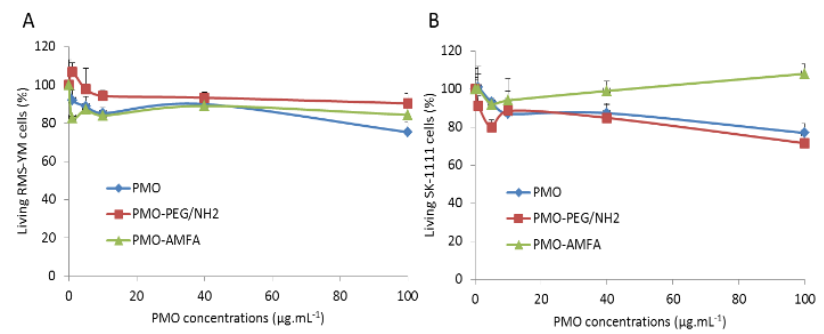

TPE-PDT PMO-AMFA induced 58\% cancer cell death. Importantly, the addition of M6P inhibited totally RMS-YM cell death suggesting that M6P prevented the internalization of PMO-AMFA through the M6PR pathway (Figure 4C). This result was confirmed by two-photon fluorescence imaging demonstrating an almost total disappearance of luminescent red dots of PMO-AMFA, in presence of M6P (Figure 4D). 


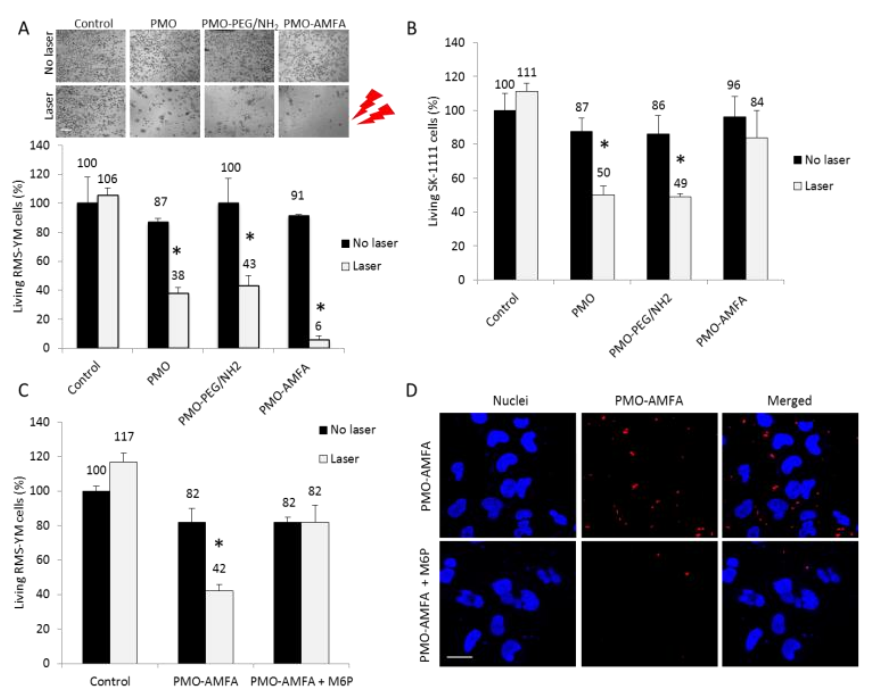

Figure 4. TPE-PDT and fluorescence imaging with PMO. (A) Cancer cells (RMS-YM) were incubated $16 \mathrm{~h}$ with PMO (40 $\left.\mu \mathrm{g} \cdot \mathrm{mL}^{-1}\right)$ and irradiated at $800 \mathrm{~nm}(3 \times 1.57 \mathrm{~s})$. Top of $(\mathbf{A})$ : pictures of living cells revealed by MTT reagent. Scale bar: 100 $\mu \mathrm{m}$. Bottom of $(\mathbf{A})$ : quantification of cell death. (B) Healthy cells (SK-1111) were incubated $16 \mathrm{~h}$ with PMO (40 $\left.\mu \mathrm{g} \cdot \mathrm{mL}^{-1}\right)$ and irradiated at $800 \mathrm{~nm}(3 \times 1.57 \mathrm{~s})$. (C) RMS-YN were incubated for $4 \mathrm{~h}$ with PMO-AMFA $\left(40 \mu \mathrm{g} \cdot \mathrm{mL}^{-1}\right)$ in the presence or absence of M6P (10 mM). (D) confocal fluorescence imaging of RMS-YM cells incubated with PMO-AMFA (40 $\left.\mu \mathrm{g} \cdot \mathrm{mL}^{-1}\right)$ in the presence or absence of M6P $(10 \mathrm{mM})$. Scale bar: $10 \mu \mathrm{m}$. Data are mean values \pm standard deviations from 3 independent experiments. *Statistically significant versus non irradiated PMO ( $p<0.05$ from Student's t test).

To study the subcellular localisation of PMO-AMFA in RMS-YM cells, a confocal imaging experiment on living cells was performed with 2 different incubation times ( $4 \mathrm{~h}$ and $16 \mathrm{~h}$ ), in presence of cell membrane (CellMask) and nucleus (Hoechst) staining. The figure 5A showed that $4 \mathrm{~h}$ incubation time was sufficient for PMO-AMFA detection mainly at cell membranes. After $16 \mathrm{~h}$ incubation time, PMO-AMFA were, largely internalized inside the cells. This observation was confirmed by flow cytometry experiments of RMS-YM cells incubated with $40 \mu \mathrm{g} \cdot \mathrm{mL}^{-1}$ PMO-AMFA for 1 to $24 \mathrm{~h}$. Figure $5 \mathrm{~B}$ showed the increasing amount of stained cells, depending on the increase of the incubation time.
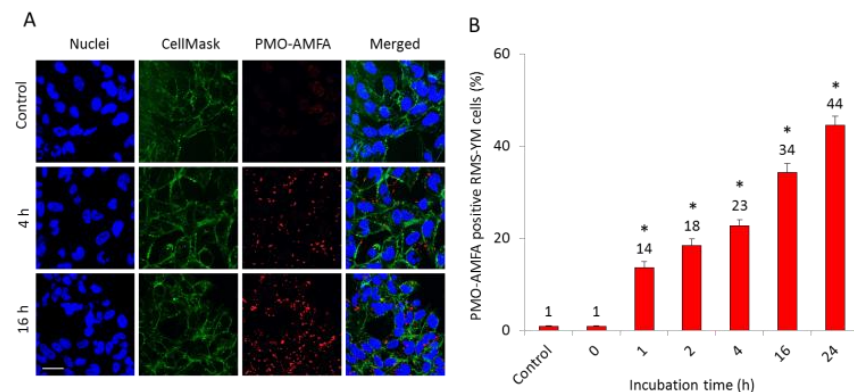

Figure 5. PMO-AMFA internalization in RMS-YM cells. (A) Confocal imaging on living cells in presence of Hoechst (nuclei stained in blue) and cell mask (membranes stained in green) after $4 \mathrm{~h}$ and $16 \mathrm{~h}$ of incubation time. Scale bar: $10 \mu \mathrm{m}$. (B) Quantification of PMO-AMFA in RMS-YM cells by flow cytometry experiments after increasing incubation times (from $1 \mathrm{~h}$ to $24 \mathrm{~h}$ ). Bar graphs are mean \pm standard deviations of 2 experiments. *Statistically significant versus control ( $p<0.05$ from Student's t test).

\section{Experimental}

\section{Material}

Cetyltrimethylammonium bromide (CTAB, 99\%), sodium hydroxide $(\mathrm{NaOH}, 97 \%)$, toluene, and ammonium nitrate $\left(\mathrm{NH}_{4} \mathrm{NO}_{3}\right)$ were purchased from Sigma-Aldrich. Ethanol (EtOH) was purchased from Carlo Erba. Aminoundecyltriethoxysilane and PEGtriethoxysilane were purchased from SIKEMIA. $p$-[N-(2-Ethoxy-3,4-dioxocyclobut-1-enyl)amino]phenyl 6-deoxy-7-hydroxycarbonyl$\alpha$-D-manno-heptopyranoside [M6C-PhSq] was synthesized as described by E. Bouffard et al. ${ }^{12}$ PMO were synthetized following the protocol previously described by C. Mauriello Jimenez et al. ${ }^{8}$

Analytical techniques 
UV-vis absorption spectra were recorded on a Hewlett-Packard 8453 spectrophotometer using correction factors supplied by the manufacturer. TEM analysis was performed on a JEOL 1200 EXII instrument. Dynamic light scattering analyses were performed using a Cordouan Technologies DL 135 Particle Size Analyzer instrument and analyzed with NanoQ software. IR spectra were recorded on a Perkin-Elmer 100 FT spectrophotometer. Zeta potential measures were performed with a Malvern Zetasizer NanoSeries Instrument.

\section{Synthesis of octasilylated porphyrin derivative}

A mixture of the octapropargyl porphyrin derivative (100 mg, $\left.9.0 \times 10^{-2} \mathrm{mmol}\right)$, bromotris(triphenylphosphine)-copper(I) ([CuBr(PPh3)3], $\left.13 \mathrm{mg}, 1.5 \times 10^{-2} \mathrm{mmol}\right)$, and anhydrous THF $(3 \mathrm{~mL})$ was placed in a $10 \mathrm{~mL}$ sealable microwave reactor, and $3-$ azidopropyltriethoxysilane $\left(178 \mathrm{mg}, 7.1 \times 10^{-1} \mathrm{mmol}\right)$ was added. Then, the tube was flushed with argon and the microwave irradiation was conducted for $30 \mathrm{~min}$ at $100^{\circ} \mathrm{C}$ (maximum power $200 \mathrm{~W}$ ). After evaporation of the solvent, octasilylated porphyrin was quantitatively obtained as a purple solid $\left(225 \mathrm{mg}, 7.25 \times 10^{-2} \mathrm{mmol}\right)$.

\section{Synthesis of Porous Porphyrin-Based Organosilica Nanoparticles (PMO)}

A mixture of CTAB $(120 \mathrm{mg}, 0.39 \mathrm{mmol})$, distilled water $(60 \mathrm{~mL})$, and $\mathrm{NaOH}(0.2 \mathrm{M}$ aqueous solution, $437 \mu \mathrm{L})$ was stirred at $80^{\circ} \mathrm{C}$ for 2 hours at $750 \mathrm{rpm}$ in a $250 \mathrm{~mL}$ three-neck round bottom flask. Then, the octasilylated porphyrin $(55 \mathrm{mg}, 0.018 \mathrm{mmol}$, in $1 \mathrm{~mL}$ of absolute ethanol) was added, and the mixture was stirred for 30 hours at $80^{\circ} \mathrm{C}$. Afterwards, the solution was cooled to room temperature while stirring. The crude mixture was centrifuged ( $20000 \mathrm{rpm}, 20 \mathrm{~min}$ ). The supernatant was removed, and the PMO were washed with ethanol and were stored at $4^{\circ} \mathrm{C}$. After extraction of the surfactant from a sample, the zeta potential was -38.3 $\mathrm{mV}$ (DLS, $\left.245 \mathrm{~nm}, \mathrm{H}_{2} \mathrm{O}\right)$.

\section{Synthesis of PMO-PEG/ $\mathrm{NH}_{2}$ nanoparticles}

After centrifugation, PMO $(48.8 \mathrm{mg})$ were resuspended in $6 \mathrm{ml}$ of toluene at $100^{\circ} \mathrm{C}$. Then a mix of 11 -aminoundecyltriethoxysilane ( $29.3 \mathrm{mg}-87.8 \mu$ moles) and PEG-triethoxysilane ( $36 \mathrm{mg}-87.8 \mu$ moles) was dissolved in $1 \mathrm{~mL}$ of toluene and added to the NPs. 20 $\mu \mathrm{L}$ of water were added to the reaction. The reaction was kept under stirring overnight at $100^{\circ} \mathrm{C}$. Then, it was cooled down to room temperature and centrifuged for 30 minutes at $20000 \mathrm{rpm}$. The supernatant was removed and the solid was washed with EtOH leading to $40 \mathrm{mg}$ of grafted PMO-PEG/NH 2 in EtOH. DLS measurement in water showed a hydrodynamic diameter of $443 \mathrm{~nm}$. Zeta potential in water gave a value of $+36.5 \mathrm{mV}$. After extraction of the surfactant from a sample, the zeta potential was $+18.3 \mathrm{mV}$ showing the functionalization. (DLS, $310 \mathrm{~nm}, \mathrm{H}_{2} \mathrm{O}$ ).

\section{Synthesis of PMO-AMFA nanoparticles}

$10 \mathrm{mg}$ of PMO-PEG/NH were resuspended in ethanol at $50^{\circ} \mathrm{C}$. A water solution $(2 \mathrm{~mL})$ of $3.6 \mathrm{mg}$ of AMFA, more precisely a mannose 6-carboxylate with a phenyl squarate arm (M6C-PhSq), was added dropwise to the PMO. The reaction was kept under stirring at $50^{\circ} \mathrm{C}$ overnight. Then, the resulting mixture was cooled down to room temperature and centrifuged. The supernatant was then removed and the solid washed with a solution of ammonium nitrate in ethanol $(6 \mathrm{~g} / \mathrm{L})$, water, and ethanol leading to 9.3 $\mathrm{mg}$ of grafted PMO-AMFA in EtOH. DLS measurement in water showed a hydrodynamic diameter of $399 \mathrm{~nm}$. Zeta potential in water gave a value of $-22.9 \mathrm{mV}$ in agreement with the functionalization with AMFA.

\section{AMFA grafting quantification}

The amount of AMFA grafted on PMO was determined by HPLC measurement in the supernatant using projection with reference solution of AMFA at different concentrations. We calculated indirectly the grafting efficiency by separating the nanoparticles out of the suspension with ultracentrifugation at the end of the reaction, and measured AMFA concentration in the supernatant with HPLC. We performed a calibration curve with the HPLC and took a reading for our supernatant. One $\mu \mathrm{L}$ of solution of subsequent dilutions from 0.84 to $0.1 \mu \mathrm{g} / \mathrm{mL}$ of AMFA, prepared in water / ethanol, was injected to HPLC Agilent 1260 infinity on a Kinetex EVO column C18 $1.7 \mu \mathrm{M} 100 \AA 50 \times 2.1 \mathrm{~mm}$. One $\mu \mathrm{L}$ of the supernatant was injected and gave us the quantification of non-grafted AMFA. The amount of grafted AMFA is $66 \mu \mathrm{g}$ of AMFA per mg of PMO. The mobile phase consisted of a mixture of acetonitrile and water with trifluoroacetic acid and was eluted at a flow rate of $0.5 \mathrm{~mL} / \mathrm{min}$. The analysis was performed at $298 \mathrm{~nm}$, and run time was about $11 \mathrm{~min}$. The chromatographic data analysis was performed using Agilent OpenLAB Software. Linearity was determined through the construction of three calibration curves using five AMFA concentrations at 3 wavelengths specific of AMFA absorbance $(298,223$ and $198 \mathrm{~nm})$. Linear least squares methodology was applied to calculate the calibration equation and correlation coefficient.

\section{Cell Culture}

Rhabdomyosarcoma cell lines Rh30 were obtained from ATCC; Rh4, Rh18, Rh36, and RD from Peter Houghton (The Research Institute at Nationwide Children's Hospital, Columbus OH); RMS, RMS-YM from Janet Shipley (The Institute of Cancer Research, London, UK); JR, Rh28 from Corinne Linardic (Duke University School of Medicine, Durham, NC); Rh5 from Susan Ragsdale (St.Jude Children's Research Hospital, Memphis, TN); RUCH-3 from Beat Schäfer (University Children's Hospital, Zurich, Switzerland); TTC442 from Timothy Triche (Children's Hospital of Los Angeles, Los Angeles, CA); SK-1111 normal myoblasts from CookMyoSite, and MH38 normal myoblasts provided by G. Carnac (Inserm U1046-UMR CNRS 9214, Montpellier, France) were used. RMS cells were cultured in DMEM medium, except for PMOsPOR nanoparticle experiments in which RMS-YM, RD and RMS were cultured in RPMI-1640 medium supplemented with $10 \%$ FBS and 1\% penicillin/streptomycin. SK-1111 and MH38 were cultured in Ham F10 medium plus $20 \%$ fetal bovine serum, $1 \%$ insulin, $25 \mathrm{ng} \cdot \mathrm{mL}^{-1} \mathrm{FGF}, 10 \mathrm{ng} \cdot \mathrm{mL}^{-1} \mathrm{EGF}$ and $1 \%$ penicillin/streptomycin. All cell types were allowed to grow in humidified atmosphere at $37^{\circ} \mathrm{C}$ under $5 \% \mathrm{CO}_{2}$. 
To study the expression level of M6PR, RMS-YM, RD, RMS, SK-1111 and MH38 were subjected to Western blot analysis. The cells were harvested, washed three times in PBS and lysed by three freeze-thaw cycles in buffer containing $50 \mathrm{mM} \mathrm{HEPES}, 150 \mathrm{mM} \mathrm{NaCl}$, $1 \mathrm{mM}$ EDTA, $2.5 \mathrm{mM}$ EGTA, 0,1\% Tween 20,10\% glycerol, $1 \mathrm{mM} \mathrm{NaF}, 1 \mathrm{mM} \mathrm{NaNO}, 10 \mathrm{mM}$ glycerophosphate and protease inhibitors (dilution 1:25 Complete, Roche Diagnostics). The lysates were precleared by centrifugation at $10,000 \times \mathrm{g}$ for $15 \mathrm{~min}$ at $4^{\circ} \mathrm{C}$. Samples were tested for protein concentration by the Bradford method and equal amounts $(25 \mu \mathrm{g})$ of cell extract and $1 \mu \mathrm{g}$ bovine purified M6PR were resolved by $12 \%$ SDS-PAGE electrophoresis. After blotting, the gel was transferred onto PVDF membrane and M6PR protein was detected by probing with anti-human M6PR (cation independent) antibody (dilution 1:50000, Abcam). $\beta$-actin detected by a monoclonal mouse antibody was used as the loading control. Immunoblotting was performed using secondary antibody coupled with horseradish peroxidase and revealed by ECL detection system (Amersham).

\section{Proteomic analysis}

Membrane proteins were enriched from $80-90 \%$ confluent cells plated in six $15 \mathrm{~cm}$ dishes, following a two-step centrifugation protocol ${ }^{13}$. After gel separation, and in-gel digestion, peptides were loaded onto HPLC-MS ${ }^{14}$. Data acquisition was made in data dependent mode with precursor ion scans recorded in the Fourier transform detector (FT) with resolution $\geq 60000$ (at $\mathrm{m} / \mathrm{z}-400$ ) and fragment spectra of the most intense precursor ions in an Orbitrap (QE). For protein quantification, we relied on the MaxQuant built-in label-free quantification (LFQ) algorithm ${ }^{15}$ and also applied a top3 peptide approach ${ }^{14,16}$. For top3, all peptide form identifications within a sample set in the evidence output file from MaxQuant were median normalized before imputation of missing values from the normal distribution of LOG2-transformed peptides using a down shift of 1.8 and a width of 0.3 standard deviations, a left-censored imputation strategy set as default in Perseus software (version1.5.5.3) ${ }^{17}$. Missing value imputation was carried out when there were at least two peptide form identifications in all technical replicates from the same sample, otherwise the intensity was set to zero according to recommendations ${ }^{18}$. The three most intense peptide intensities were then summed to the protein group iTop3 intensity.

\section{Cytotoxicity Measurement}

For cytotoxicity analysis, RMS-YM and SK-1111 cells were seeded into a 96 well plate, 2000 cells per well in $200 \mu \mathrm{L}$ of culture medium and allowed to grow for $24 \mathrm{~h}$. Then cells were treated with increasing concentrations of nanoparticles (from 1 to 100 $\left.\mu \mathrm{g} . \mathrm{mL}^{-1}\right)$. Three days after treatment, a MTT assay was performed to determine the cell viability. Briefly, cells were incubated for 4 $\mathrm{h}$ with $0.5 \mathrm{mg} \cdot \mathrm{mL}^{-1}$ of MTT (3-(4,5-dimethylthiazol-2-yl)-2,5-diphenyltetrazolium bromide; Promega) in media. The MTT/media solution was then removed and the precipitated crystals were dissolved in EtOH/DMSO (v/v). The solution absorbance was read at $540 \mathrm{~nm}$ in a microplate reader. All values are reported to the control values (without any treatment) which are considered at $100 \%$ of living cells.

\section{Two-Photon Excited Photodynamic Therapy}

RMS-YM and SK-1111 cells were seeded into a 384 multi-well glass-bottomed plate (thickness $0.17 \mathrm{~mm}$ ) with a black polystyrene frame at a concentration of 1000 cells per well in $50 \mu \mathrm{L}$ of culture medium, and allowed to grow for $24 \mathrm{~h}$. Then, cells were treated with nanoparticles $\left(40 \mu \mathrm{g} \cdot \mathrm{mL}^{-1}\right)$ for $16 \mathrm{~h}$. For M6P competitive inhibition assay, the cells were incubated or not with $10 \mathrm{mM}$ of M6P for 10 min prior to the incubation with PMO-AMFA $\left(40 \mu \mathrm{g} \cdot \mathrm{mL}^{-1}\right)$ for $4 \mathrm{~h}$. The cells were submitted or not to laser irradiation with the LSM 780 live confocal microscope (Carl Zeiss Microscope) at $800 \mathrm{~nm}$ by 3 scans of $1.57 \mathrm{~s}$ duration in 4 different areas of the well with a focused laser at a maximum laser power (lase power input 3W). The laser beam was focused by a microscope objective lens (Carl Zeiss 10×/0.3 EC Plan-Neofluar). After 2 days, the MTT assay was performed as previously described and was corrected according to the following formula: Abs control $-2 \times$ (Abs control - Abs nanoparticles).

\section{Two-photon fluorescence imaging}

RMS-YM cells were grown on tissue culture dish with cover glass bottom (FluoroDish from WPI) in complete culture medium. The next day, the cells were treated or not with $10 \mathrm{mM}$ of M6P for $10 \mathrm{~min}$, then the cells were incubated with PMO-AMFA (40 $\mu \mathrm{g} . \mathrm{mL}^{-1}$ ) for $4 \mathrm{~h}$. Fifteen minutes before the end of incubation, cells were loaded with Hoechst 33342 (5 $\mu \mathrm{g} \cdot \mathrm{mL}^{-1}$, Invitrogen) for nuclear staining and with green CellMask ( $5 \mu \mathrm{g} \cdot \mathrm{mL}^{-1}$, Invitrogen, Cergy Pontoise, France) for membrane staining. Before visualization, cells were washed three times with cell media. Cells were examined under LSM 780 live confocal microscope (Carl Zeiss Microscope) and excited at $488 \mathrm{~nm}$ for membranes at $760 \mathrm{~nm}$ for nuclei and $800 \mathrm{~nm}$ for PMO-AMFA. All images were performed with a high magnification (63×/1.4 OIL DIC Plan-Apo).

\section{Flow cytometry}

RMS-YM cancer cells were seeded on 6-well plate during $24 \mathrm{~h}$. Then, cells were treated or not with $40 \mu \mathrm{g} \cdot \mathrm{mL}^{-1}$ of PMO-AMFA for 0 , $1,2,4,16$ and $24 \mathrm{~h}$. After treatment, cells were washed thrice with culture medium, harvested and centrifuged (1300 rpm, $5 \mathrm{~min}$ ). Cell pellets were re-suspended in PBS enriched with $\mathrm{CaCl}_{2}{ }^{+}, \mathrm{MgCl}_{2}{ }^{+}$. Flow cytometry determination of PMO-AMFA positive cells was done by FACS Novocyte Flow Cytometer (ACEA Biosciences Inc.) with a minimum of 5000 cells collected (excitation laser $561 \mathrm{~nm}$; Filter: $660 \pm 20 \mathrm{~nm}$ ).

\section{Statistical analysis}

Statistical analysis was performed using the Student's $t$ test to compare paired groups of data. A p-value of $<0.05$ was considered to be statistically significant.

\section{Conclusions}


In this study, we have demonstrated that M6PR was a new target for rhabdomyosarcoma. In fact, we have observed an over-expression of this receptor in a panel of RMS cells of different subtypes (embryonal and alveolar) allowing to differentiate between cancer cells and healthy cells. The targeting of M6PR was performed using AMFA and more precisely by the grafting of a carboxylate analogue of mannose 6-phosphate on the PMO.

Altogether, the results presented here showed that PMO-AMFA were highly efficient for TPE-theranostic of RMS-YM cells by a mechanism involving M6PR dependent endocytosis. Moreover, PMO-AMFA did not show any effect on healthy cells demonstrating the specificity of the targeting toward cancer cells. Targeted TPE-PDT could be considered as a new promising therapeutic strategy for rhabdomyosarcoma.

\section{Conflicts of interest}

There are no conflicts to declare.

\section{Acknowledgments}

Grafting quantification was performed with technical support of the Synbio3 platform, which is supported by GIS-IBISA ITMO Cancer (Plan Cancer 2014-2019). We acknowledge the imaging facility MRI, member of the national infrastructure France-Biolmaging supported by the French National Research Agency (ANR-10-INBS-04, «Investments for the future»).

\section{Notes and references}

1. L. Zhang, P. Marrano, S. Kumar, M. Leadley, E. Elias, P. Thorner and S. Baruchel, Clin. Cancer Res., 2013, 19, 5972-5983.

2. M. Roveri, A. Pfohl, P. Jaaks, N. Alijaj, J. C. Leroux, P. Luciani and M. Bernasconi, Nanomedicine (Lond), 2017, 12, 11351151.

3. M. G. Krukemeyer, V. Krenn, M. Jakobs and W. Wagner, J. Drug Target., 2012, 20, $185-193$.

4. S.-L. Wang, H.-H. Yao, L.-L. Guo, L. Dong, S.-G. Li, Y.-P. Gu and Z.-H. Qin, Cancer Genet. Cytogenet., $2009,190,8-14$.

5. X. Huang, H. Townley and H. Townley, Nanobiomedicine (Rij), 2016, 3, 4.

6. A. A. Taha, S. M. H. Al-Jawad and L. F. A. Al-Barram, J. Cluster Sci., 2019, 30, 403-414.

7. V. Rengaswamy, D. Zimmer, R. Suss and J. Rossler, J. Control. Release, 2016, 235, 319-327.

8. O. Vaillant, K. El Cheikh, D. Warther, D. Brevet, M. Maynadier, E. Bouffard, F. Salgues, A. Jeanjean, P. Puche, C. Mazerolles, P. Maillard, O. Mongin, M. Blanchard-Desce, L. Raehm, X. Rebillard, J.-O. Durand, M. Gary-Bobo, A. Morere and M. Garcia, Angew. Chem., Int. Ed., 2015, 54, 5952-5956.

9. C. Mauriello Jimenez, D. Aggad, J. G. Croissant, K. Tresfield, D. Laurencin, D. Berthomieu, N. Cubedo, M. Rossel, S. Alsaiari, D. H. Anjum, R. Sougrat, M. A. Roldan-Gutierrez, S. Richeter, E. Oliviero, L. Raehm, C. Charnay, X. Cattoen, S. Clement, M. Wong Chi Man, M. Maynadier, V. Chaleix, V. Sol, M. Garcia, M. Gary-Bobo, N. M. Khashab, N. Bettache and J. O. Durand, Advanced Functional Materials, 2018, 28, 1800235.

10. S. Biswas, H.-Y. Ahn, M. V. Bondar and K. D. Belfield, Langmuir, 2012, 28, 1515-1522.

11. J. R. Starkey, A. K. Rebane, M. A. Drobizhev, F. Q. Meng, A. J. Gong, A. Elliott, K. Mclnnerney and C. W. Spangler, Clin. Cancer Res., 2008, 14, 6564-6573.

12. E. Bouffard, C. Mauriello Jimenez, K. El Cheikh, M. Maynadier, I. Basile, L. Raehm, C. Nguyen, M. Gary-Bobo, M. Garcia, J.O. Durand and A. Morère, Int. J. Mol. Sci., 2019, 20, 2809.

13. P. H. Lin, R. Selinfreund, E. Wakshull and W. Wharton, Biochemistry, 1987, 26, 731-736.

14. S. Braga-Lagache, N. Buchs, M. I. lacovache, B. Zuber, C. B. Jackson and M. Heller, Mol. Cell. Proteomics, 2016, 15, 36403652 .

15. J. Cox, M. Y. Hein, C. A. Luber, I. Paron, N. Nagaraj and M. Mann, Mol. Cell. Proteomics, 2014, 13, $2513-2526$.

16. E. Ahrne, L. Molzahn, T. Glatter and A. Schmidt, Proteomics, 2013, 13, 2567-2578.

17. S. Tyanova, T. Temu and J. Cox, Nat. Protoc., 2016, 11, 2301-2319.

18. C. Lazar, L. Gatto, M. Ferro, C. Bruley and T. Burger, J. Proteome Res., 2016, 15, 1116-1125.

19. D. Warther, C. M. Jimenez, L. Raehm, C. Gerardin, J.-O. Durand, A. Morere, K. El Cheikh, A. Gallud, M. Gary-Bobo, M. Maynadier and M. Garcia, RSC Adv., 2014, 4, 37171-37179. 